Review

\title{
Inflammatory Response Following Diffuse Axonal Injury
}

\author{
Yu Lin ${ }^{1}$, Liang Wen ${ }^{2,}$ \\ 1. School of Medicine, Zhejiang University City College, China; \\ 2. Department of Neurosurgery, First Affiliated Hospital, College of Medicine, Zhejiang University, China.
}

$\triangle$ Corresponding author: Liang Wen MD. Department of Neurosurgery, First Affiliated Hospital, College of Medicine, Zhejiang University, No.79 Qingchun Road, Hangzhou City 310003, Zhejiang Province, PR China. Phone: 86571-87236803 Fax: 86571-87072577 Correspondent E-mail: wenliang@zju.edu.cn.

(c) Ivyspring International Publisher. This is an open-access article distributed under the terms of the Creative Commons License (http://creativecommons.org/ licenses/by-nc-nd/3.0/). Reproduction is permitted for personal, noncommercial use, provided that the article is in whole, unmodified, and properly cited.

Received: 2012.10.20; Accepted: 2013.03.06; Published: 2013.03.13

\begin{abstract}
DAl is a leading cause of the patient's death or lasting vegetable state following severe TBI, and up to now the detailed mechanism of axonal injury after head trauma is still unclear. Inflammatory responses have been proved to be an important mechanism of neural injury after TBI. However, most of these studies are concerned with focal cerebral injury following head trauma. In contrast to focal injury, studies on the inflammatory reaction following DAl are only beginning. And in this article, we aimed to review such studies. From the studies reviewed, immune response cells would become reactive around the sites of axonal injury after DAl. Besides, the concentrations of several important inflammatory factors, such as IL-I family, IL-6 and TNF-a, increased after DAI as well, which implies the participation of inflammatory responses. It can be concluded that inflammatory responses probably participate in the neural injury in DAI, but at present the study of inflammatory responses following DAl is still limited and the clear effects of inflammatory response on axonal injury remain to be more explored.
\end{abstract}

Key words: Traumatic brain injury, Diffuse axonal injury, Inflammatory response.

\section{Introduction}

Inflammatory responses following neural injury have been suggested as an important mechanism in several types of neural system disease including TBI $[1,2]$, cerebral hemorrhage ${ }^{[3]}$, cerebral infarction $[4,5]$, and multiple sclerosis ${ }^{[6]}$. Clinical and experimental studies of TBI have demonstrated that such injury induces a robust inflammatory response that involves the accumulation of various types of inflammatory reactive cells as well as the expression of a number of inflammatory factors. The recruitment of inflammatory reactive cells has been identified in or around cerebral contusion lesions in conjunction with microglia, polymorphonuclear granulocytes, macrophages, and T-lymphocytes [2,7-9]. Moreover, many inflammatory factors, such as histamine, PGs, SP, and several cytokines, are increasingly expressed in CSF and/or blood around contusion lesions [10-15]. However, most of these studies are concerned with focal cerebral injury following head trauma. DAI, which is a leading cause of patient death and is implicated in lasting vegetable states following severe TBI, also occurs subsequent to neural injury and, as of yet, there is no specific therapy effectively treating this pathology [16]. Important$l y$, more and more emerging evidences indicate that axonal injury develops more frequently in TBI than previously estimated [17,18].

Focal injury following TBI is relatively straightforward and typically involves cerebral contusions and lacerations sometimes combined with lesion formation. Cerebral contusions are typical pathologic changes resulting from hemorrhagic lesions within the gray matter or at the gray-white matter interface. In contusional and pericontusional domains, secondary necrotic and apoptotic neuronal death have been 
consistently identified [19-22]. As mentioned above, the inflammatory response following head trauma is believed to be an important mechanism of such secondary neuronal death. In contrast to focal injury following TBI, axonal injuries are scattered throughout subcortical white matter in areas such as the corpus callosum, thalamus, and brain stem [23-26]. Studies from the last 20 years have revealed that direct mechanical forces do not completely tear axons and result in axonal retraction balls but rather stimulate and induce progressive changes that impede axonal transport, which subsequently results in the local swelling of the axon prior to detachment from its downstream segment [27-29]. Furthermore, focal swelling of the axon ensues via the continued delivery of substances during normal transport kinetics, which leads to the collapse and detachment of the axon at this point of focal swelling [27, 29-31]. Thus, similar to focal injury, axonal injury also has a deleterious secondary impact following head trauma. In contrast to focal injuries, studies on the inflammatory reaction following DAI are only beginning. Nonetheless, these studies have resulted in a massive amount of helpful information concerning inflammatory reactions in DAI that is not the same as focal injury. These studies on DAI-induced inflammatory responses may help us understand this disorder better and can possibly provide methods by which to develop efficient therapies for it. The current paper reviews studies concerning the inflammatory response following DAI.

Compared to focal injury models, an experimental animal model of DAI is relatively difficult to set up. There are some excellent reviews about experimental models of DAI [32,33]. These models mainly include the instant rotational injury model, the impact accelerative injury model, the lateral fluid percussion injury model, the controlled cortical impact model, the nerve stretch injury model [32], and central fluid percussion injury model. Most of these cause not only axonal injury but also result in focal injuries, and thus it is important to clarify the precise type of injury to which the inflammatory actions are responding. For example, at present, the model introduced by Marmarou and colleagues ${ }^{[32,34]}$ is a typical and popular option among DAI studies, but it not only results in DAI in different white matter regions but also multiple focal cerebral injuries. Hence, in most studies, the detection of inflammatory responses was conducted around sites of possible axonal injury to exclude the influences of focal injury. In addition, some studies have utilized double markers of axonal injury and inflammatory responses to more accurately observe the phenomenon [35,36].

\section{Cellular Immune Response}

Most of the recent animal TBI models induce focal injury on the cortex or other parts of the brain through controlled impact. A robust inflammatory response involving the activation of glia, neurons, and cerebral accumulation of blood leukocytes follows [9], however, this inflammatory cell response is not the same as that following DAI.

Microglial cells are the main immune response in the central nervous system and a frequent target of investigation in DAI experimental models. Venkatesan et al. [37] used Galectin-3/Mac-2 as a marker of a subpopulation of activated microglia involved in myelin degradation. In that study, a closed skull impact mouse model was utilized along with immunofluorescence staining for APP, a classic marker of axonal injury, and showed multiple axonal injuries at dorsal midline white matter tracts. The results also indicated that immunopositive microglia significantly increased within the corpus callosum; a change that was sustained until 28 days post-TBI and was most obvious 24 hours post-TBI. Oehmichen et al. ${ }^{[36]}$ used an immunohistochemical double-labeling technique for the simultaneous demonstration of beta-APP for axonal injury and CD68 for microglia to observe microglia among 40 patients who survived TBI for more than 3 hours and up to 15 days. Among approximately half of the included cases with survival intervals of 5 to 15 days, there was a moderate microglial reaction in regions of injured axons positive for beta-APP. Similar results were found in other clinical and experimental studies following axonal injury $[38,39]$.

Csuka et al. [40], using the DAI model introduced by Marmarou [34], reported an intensification of GFAP-stained reactive astrocytes 4 to 8 hours following TBI and, except for sites of focal cortical injury, this response was primarily found in the thalamus and hypothalamus where the maximal expression of signs of axonal injury were apparent at 48 hours for up to 2 weeks after the trauma. Activated microglia (stained by OX42) was found in cortex and hippocampus as early as 4 hours, and up-regulation of MHC class II (OX6 positive) was evident in white matter tracts at 24 hours following injury. Macrophage (ED1 positive) numbers increased in the meninges and perivascularly from 24 to 48 hours for up to 2 weeks, but this infiltration was marginal. Besides, that no parenchymal infiltration of lymphocytes and granulocytes was observed throughout the brain at any time point after trauma showed the absence of the two populations of immune cells. In contrast to Csuka et al. [40], studies of focal injury following head trauma found that these two types of immune cells emerged 
in and around the sites of contusions due to dysfunction of the BBB and are important for the subsequent inflammatory response ${ }^{[41-44]}$.

Kelley et al. [35] conducted a more detailed study on this topic with the induction of DAI via moderate midline/central fluid percussion injury and double-labeling strategies to observe immune cells and axonal injury simultaneously. In the acute phase (within 48 hours post-injury), activated microglial cells and macrophages were observed at axonal injury sites, including the hippocampal parenchyma. Subsequently, the number of activated microgila increased by 48 hours post-injury, and these activated microglia cells scattered near the sites of axonal injury. Besides, the immunophenotypic macrophages persisted as well. Seven days following injury, enhanced microglial/macrophage immunoreactivity still could be able to be observed within diffuse injured axonal sites. And within thalamus immunophenotypic the number of macrophages even increased. In addition, electron microscopy evaluation revealed that activated microglia and macrophages exhibit consistent immune cell interactions in relation to injured axons even beyond 7 days. Here, the authors concluded that the activation of microglia shares a spatiotemporal relationship with axonal injury although no clear interactions were observed. Other studies have found a similar cellular response following DAI $[45,46]$ including the one introduced by Helelwell and his colleagues [46], who demonstrated that hypoxia perpetuates axonal pathology and cellular inflammation.

From such studies, it appears that the proliferation and activation of resident glial cells and peripheral macrophages are the main immune cell responses following DAI which is similar to responses to focal injury following head trauma ${ }^{[47]}$. However, in axonal injury, lymphocytes and granulocytes are absent from this process, which implies different patterns of immune injury comparing to focal injury. The activation of immune cells can be detected as early as 4 hours after head trauma and can last from 7 to 28 days in DAI. Although the number of studies on immune cell activation following DAI is limited, these discoveries strongly imply that inflammatory cells are involved in DAI.

\section{Cytokines}

Cytokines are proteins secreted from cells that function as a means of communication between cells in both a paracrine and endocrine fashion. They are important for the repair and the defense of tissue following trauma. The expression of various types of cytokines increases after head trauma.
Well-investigated cytokines include the IL-1 family, IL-6, IL-10, and TNF-a, which likely play an important role in inflammatory reactions following TBI [1,2,37,48-52].

The IL-1 family, including IL-1a, IL-1 $\beta$, and IL-18, is one of the best investigated pro-inflammatory cytokines and a number of studies investigating focal injury have identified its participation in secondary neural injury. Ciallella et al. [53] constructed a controlled cortical impact injury model and used APP to mark axonal injury. In the early stages after trauma, an increase in APP was obvious in white matter axonal tracts. In the hippocampus and cortical areas where the APP increase was significant, the expression of IL-1 $\beta$ also increased and reached its peak by 6 hours after trauma. Lu et al. ${ }^{[54]}$ used the model introduced by Marmarou [34] and observed a rapid increase in expression in both IL-1 $\alpha$ and IL-1 $\beta$. However, they only detected cortical expression changes and did not confirm the existence of axonal injury. It is well-known that the IL-1 family has extensive inflammatory functions such as stimulating T-cells and macrophages as well as leading to the secretion of other cytokines and chemokines. In addition, Campbell et al. ${ }^{[55]}$ also reported that the overexpression of IL-1 $\beta$ has a strong relation with axonal injury.

Hans et al. [56], also using the model introduced by Marmarou [34], found widespread axonal injury, which was confirmed in the white matter by immunohistochemical examination using an antibody against neurofilaments. In that study, IL-6 activity increased in the CSF just 1 hour following DAI and reached maximum levels between 2 to 4 hours, after which it returned to control values within 24 hours. Serum IL-6 activity reached peak levels 4 hours following DAI but its concentration was much lower than that in the CSF. Moreover, IL-6 mRNA and protein expression were also positive at sites where axonal injury was observed. Similarly, Rhodes et al. [57] observed an intense area of IL- 6 activation below the hippocampus following DAI using the model introduced by Marmarou [34]. IL-6 is an important inflammatory cytokine and has a wide range of effects. It affects both pro-inflammatory and anti-inflammatory responses via regulation of the activity of immunocytes such as neutrophils, lymphocytes, and NK-cells as well as the induction of the release of soluble TNFR and IL-1 receptor antagonists [58, 59]. These two studies found that, subsequent to DAI, the expression of IL-6 increased quickly at the sites of axonal injury. This cytokine has been used as an indicator of the severity of the inflammatory response in many studies ${ }^{[60]}$.

Kita et al. ${ }^{[61]}$ used a midline fluid percussion rat model to develop axonal injury in the central nervous system after which axonal injury was identified using 
an electron endoscope to view the corpus callosum and brain stem. TNF-a concentrations in the tissue of both the brain stem and corpus callosum gradually increased during the first hour following the induction of DAI and rose to maximal levels during the third hour, after which they gradually decreased. TNF-a immunoreactivity was primarily detected in the lysosomes of glia such as microglia, perivascular astrocytes, and oligodendroglia. Khuman and colleagues [62] also observed an increase in TNF-a expression in the hippocampus and related cortices 3 to 6 hours following head trauma in an experimental animal model. They used a closed head injury model with a weight drop and free rotational head movement. Axonal injury was identified in the cortex and the periventricular white matter of injured mice using APP immunohistochemistry and electron microscopy. The activation of astrocytes and microglia was also observed. In another study, Yan and colleagues [63] used the model introduced by Marmarou ${ }^{[34]}$ and, after trauma, found that the expression of IL- $1 \beta$, IL- 6 , and TNF-a increased significantly. They also detected the expression of these pro-inflammatory cytokines in rats receiving DAI plus hypoxia and found that neuroinflammation was enhanced compared to simple DAI. TNF-a is a classic pro-inflammatory factor and its action stimulates immunocytes such as NK-cells and macrophages/monocytes, and promotes the secretion of several inflammatory factors such as NO, platelet activation factor, ICAM, thromboxan A2, and prostaglandin E2 [64]. It can also regulate cell apoptosis by binding to TNFR1 [65]. TNF-a is also able to directly induce primary demyelination and oligodendrocyte apoptosis in central nervous system disease [66-68]. Such results suggest that TNF-a may contribute to the pathogenic mechanism of DAI formation following fluid percussive brain injury.

ICAM-1 is an important adhesion molecule in the mediation of leukocyte migration [69]. In addition, in the central nervous system, chemokines such as MIP-2 and MCP-1 play an important role in the regulation of immunocytes [70,71]. Rancan et al. [72], using an impact-acceleration model of DAI introduced by Hans et al. [56], demonstrated the expression of these cytokines after DAI. The expression of ICAM-1 increased 16 hours following construction of the animal model and reached maximum levels during the fourth day. This increase was most obvious in the dorsal cortex, basal cortex, thalamus, and corpus callosum. Despite the marked upregulation of ICAM-1, there was no infiltration of neutrophils detected. The concentration of MCP-1 was significantly elevated after DAI but the concentration of MIP-2 did not show a significant difference compared to control brains.
However, in focal injury, the expression of both MCP-1 and MIP-2 increased [71]. MCP-1 is important for the recruitment of blood-borne monocytes ${ }^{[73]}$ and MIP-2 is a powerful chemotactic factor for neutrophils [74]. The changes in expression for these two chemokines following DAI is quite consistent with the results of Csuka's study [40] mentioned above.

Prostaglandin is an important inflammatory factor for many types of neural injury [11,75]. Its synthesis is regulated by the enzyme COX, which has at least two isoforms: COX-1 and COX-2 [76]. In addition to the regulation of inflammatory reactions, COX-2 is able to produce many kinds of effects including ROS release, cerebrovascular spasm, and neuroendocrine influences [77-79]. The expression of COX-2 increases in focal injury following head trauma ${ }^{[80,81]}$ and Cernak et al. [82] found changes of COX-2 expression after DAI in rats. That study utilized the model introduced by Marmarou ${ }^{[34]}$ and detected the expression of COX-2 in the hippocampus and parietal cortex using immunohistochemistry and Western blotting. The expression of COX-2 increased rapidly in the hippocampus as early as 3 hours following DAI, and these changes lasted at least 12 days. In the cortex, the upregulation of COX-2 expression was less significant and had a shorter duration. Moreover, nimesulide, a COX-2 inhibitor, was used for the detection of neural function outcomes following DAI. Animals administered nimesulide exhibited significant improvement in cognitive function compared to vehicle controls and motor deficits were attenuated as well but without a significant difference. However, the authors did not compare the changes of axonal injury after administration of nimesulide.

Although studies on the expression of cytokines following DAI are still only beginning, their findings imply that particular types of cytokines participate in the process of axonal injury following head trauma, similar to focal injury. However, several studies have revealed that, without neutrophil infiltration, the changes in cytokines following DAI are probably different from those following focal injury.

\section{Complement}

The activation of a complement system is an important part of the innate immunologic response against infection and injury. There are many studies concerning focal injury that have investigated complements and it has been well documented that complements delay neural injuries following head trauma [83]. All three pathways, including classical, lectin, and alternative pathways, converge in the formation of C3-convertases [1]. The formation of C5-convertase occurs via binding of $\mathrm{C} 3 \mathrm{~b}$ which leads to a proteolytic 
cleavage of complement C5 to the potent anaphylatoxins $\mathrm{C} 5 \mathrm{a}$ and $\mathrm{C} 5 \mathrm{~b}$. Then, the terminal pathway of complement activation is initiated by the aggregation of $\mathrm{C} 5 \mathrm{~b}$ to $\mathrm{C} 6, \mathrm{C} 7$, and $\mathrm{C} 8$ molecules and the subsequent membrane pore formation via accumulation of multiple C9 molecules, which leads to cell lysis [1].

Regarding axonal injury, Stahel et al. [84] found C5a expression in the central nervous system after induction of DAI using the Marmarou experimental model [34]. Four hours after trauma, immunoreactive cells expressing $\mathrm{C} 5 \mathrm{aR}$ mRNA were observed in the meninges and lateral ventricles, and the number gradually increased for up to 24 hours. In the cerebral parenchyma, C5aR mRNA positive cells were observed 8 hours following injury and were widespread bilaterally throughout the cortex and cerebellum. In addition, the intensity of $\mathrm{C} 5 \mathrm{aR}$ transcript signals on neurons increased after trauma. As a typical inflammatory factor, C5a, which can be expressed by neurons throughout the cerebral cortex and cerebellum, has a multitude of effects on the inflammatory response and is believed to be a primary factor of immune responses in the central nervous system ${ }^{[85,86] .}$

\section{Other Studies}

Risling et al. [87] investigated gene expression following TBI. Three different models of head trauma were established in that study, including a model of DAI using controlled rotation injury, which was introduced by Davidson et al. [88]. This model is closer to simple axonal injury without focal cerebral trauma relative to the brain impact ${ }^{[32]}$. Within this model, the rat's hippocampus was dissected out for gene expression detection using Affymetrix standard procedures for targeting RNA. There were changes in the expression of a large number of gene families after DAI including inflammatory genes in the hippocampus, and such changes were not the same as those of the model of focal injury.

Myelin debris can recruit leukocytes and stimulate macrophages to express pro-inflammatory molecules [89], and after DAI, may be found around the site of axonal injury [35]. The hypothesis was raised that myelin debris from injured axons triggers undesirable inflammation and upregulates the expression of various types of pro-inflammatory cytokines, which would probably lead to further axonal injury [90].

In addition, studies that delivered anti-inflammatory or immunosuppressive agents such as cyclosporin A, PACAP, and SP antagonists to experimental animals after head trauma found that the axonal injury was significantly attenuated [91-94]. However, In Homsi and colleagues's study [95], the microglia activation was depressed significantly with minocycline, while with simultaneous reduced focal injury lesion, but axonal injury was not able to attenuated.

In conclusion, similar to focal injuries following TBI, inflammatory responses probably participate following DAI. Based on the studies reviewed here, following head trauma, various types of immune response cells become reactive around the sites of axonal injury and share a spatiotemporal relationship with axonal injury. In addition, the concentration of several inflammatory factors including cytokines and complements increase after DAI, which implies the involvement of inflammatory responses. Besides, based on present studies, the inflammatory responses following DAI are not as same as those following focal injury.

However, the study of inflammatory responses following DAI is still limited and the clear relationship and effects of inflammatory response on axonal injury remain to be more explored. Furthermore, because most recent experimental animal models not only lead to axonal injury but also other types of injury, it is important and necessary to determine which injury types induce inflammatory responses.

\section{Abbreviations}

BBB: blood-brain barrier; CSF: cerebrospinal fluid; COX: cyclo-oxygenase; DAI: diffuse axonal injury; GFAP: glial fibrillary acidic protein; MCP: monocyte chemoattractant protein; MIP: macrophage inflammatory protein; mRNA: messenger ribonucleic acid; NGF: neural growth factor; NK-cells: natural killer cells; NO: nitric oxide; PACAP, pituitary adenylate cyclase activating polypeptide; PGs: prostaglandin synthetase; ROS: reactive oxygen species; SP: substance P; TBI: traumatic brain injury; TNF: tumor necrosis factor; TNFR: tumor necrosis factor receptor; ICAM: intercellular adhesion molecule; IL: interleukin.

\section{Acknowledgement}

This work was supported by National Nature Science Fund from National Nature Science Foundation of China (81200955) and the research fund from Education Bureau of Zhejiang Province (Y201223925).

\section{Competing Interests}

The authors have declared that no competing interest exists.

\section{References}

1. Schmidt OI, Heyde CE, Ertel W, et al. Closed head injury-an inflammatory disease? Brain Res Brain Res Rev. 2005;48:388-399.

2. Lenz A, Franklin GA, Cheadle WG. Systemic inflammation after trauma. Injury. 2007;38:1336-1345. 
3. Pradilla G, Chaichana KL, Hoang S, et al. Inflammation and cerebral vasospasm after subarachnoid hemorrhage. Neurosurg Clin N Am. 2010;21:365-379.

4. Lakhan SE, Kirchgessner A, Hofer M. Inflammatory mechanisms in ischemic stroke: therapeutic approaches. J Transl Med. 2009;7:97.

5. Whiteley W, Jackson C, Lewis S, et al. Inflammatory markers and poor outcome after stroke: a prospective cohort study and systematic review of interleukin-6. PLoS Med. 2009;6:e1000145.

6. Friese MA, Montalban X, Willcox N, et al. The value of animal models for drug development in multiple sclerosis. Brain. 2006;129:1940-1952.

7. Lynch NJ, Willis CL, Nolan CC, et al. Microglial activation and increased synthesis of complement component $\mathrm{C} 1 \mathrm{q}$ precedes blood-brain barrier dysfunction in rats. Mol Immunol. 2004;40:709-716.

8. Quattrocchi KB, Miller CH, Wagner FC, Jr., et al. Cell-mediated immunity in severely head-injured patients: the role of suppressor lymphocytes and serum factors. J Neurosurg. 1992;77:694-699.

9. Czigner A, Mihaly A, Farkas O, et al. Kinetics of the cellular immune response following closed head injury. Acta Neurochir (Wien). 2007;149:281-289.

10. Mace BE, Wang H, Lynch JR, et al. Apolipoprotein E modifies the CNS response to injury via a histamine-mediated pathway. Neurol Res. 2007;29:243-250.

11. Zhang J, Rivest S. Anti-inflammatory effects of prostaglandin E2 in the central nervous system in response to brain injury and circulating lipopolysaccharide. J Neurochem. 2001;76:855-864.

12. Vink R, Donkin JJ, Cruz MI, et al. A substance P antagonist increases brain intracellular free magnesium concentration after diffuse traumatic brain injury in rats. J Am Coll Nutr. 2004;23:538S-540S.

13. LaPar DJ, Rosenberger LH, Walters DM, et al. Severe traumatic head injury affects systemic cytokine expression. J Am Coll Surg. 2012;214:478-486.

14. Solomon D, Kim B, Scultetus A, et al. The effect of rFVIIa on pro- and anti-inflammatory cytokines in serum and cerebrospinal fluid in a swine model of traumatic brain injury. Cytokine. 2011;54:20-23.

15. Helmy A, Carpenter KL, Menon DK, et al. The cytokine response to human traumatic brain injury: temporal profiles and evidence for cerebral parenchymal production. J Cereb Blood Flow Metab. 2011;31:658-670.

16. Li XY, Feng DF. Diffuse axonal injury: novel insights into detection and treatment. J Clin Neurosci. 2009;16:614-619.

17. Li J, Li XY, Feng DF, et al. Biomarkers associated with diffuse traumatic axonal injury: exploring pathogenesis, early diagnosis, and prognosis. J Trauma. 2010;69:1610-1618

18. Sharp DJ, Ham TE. Investigating white matter injury after mild traumatic brain injury. Curr Opin Neurol. 2011;24:558-563.

19. Vlodavsky E, Palzur E, Feinsod $M$, et al. Evaluation of the apoptosis-related proteins of the BCL-2 family in the traumatic penumbra area of the rat model of cerebral contusion, treated by hyperbaric oxygen therapy: a quantitative immunohistochemical study. Acta Neuropathol. 2005;110:120-126.

20. Soustiel JF, Vlodavsky E, Zaaroor M. Relative effects of mannitol and hypertonic saline on calpain activity, apoptosis and polymorphonuclear infiltration in traumatic focal brain injury. Brain Res. 2006;1101:136-144.

21. Kim JV, Dustin ML. Innate response to focal necrotic injury inside the blood-brain barrier. J Immunol. 2006;177:5269-5277.

22. Friedrich DH, Plesnila N, Eriskat J, et al. Cerebral blood flow and the secondary growth of brain tissue necrosis after trauma. Acta Neurochir Suppl. 2000;76:257-259.

23. Ross DT, Graham DI, Adams JH. Selective loss of neurons from the thalamic reticular nucleus following severe human head injury. J Neurotrauma. 1993;10:151-165.

24. Ahn YH, Kim SH, Han BS, et al. Focal lesions of the corticospinal tract demonstrated by diffusion tensor imaging in patients with diffuse axonal injury. NeuroRehabilitation. 2006;21:239-243.

25. Chang MC, Jang SH. Corpus callosum injury in patients with diffuse axonal injury: a diffusion tensor imaging study. NeuroRehabilitation. 2010;26:339-345.

26. Farkas O, Povlishock JT. Cellular and subcellular change evoked by diffuse traumatic brain injury: a complex web of change extending far beyond focal damage. Prog Brain Res. 2007;161:43-59.

27. Povlishock JT, Katz DI. Update of neuropathology and neurological recovery after traumatic brain injury. J Head Trauma Rehabil. 2005;20:76-94.

28. Grady MS, McLaughlin MR, Christman CW, et al. The use of antibodies targeted against the neurofilament subunits for the detection of diffuse axonal injury in humans. J Neuropathol Exp Neurol. 1993;52:143-152.
29. Christman CW, Grady MS, Walker SA, et al. Ultrastructural studies of diffuse axonal injury in humans. J Neurotrauma. 1994;11:173-86.

30. Buki A, Siman R, Trojanowski JQ, et al. The role of calpain-mediated spectrin proteolysis in traumatically induced axonal injury. J Neuropathol Exp Neurol. 1999;58:365-375.

31. Buki A, Okonkwo DO, Wang KK, et al. Cytochrome c release and caspase activation in traumatic axonal injury. J Neurosci. 2000;20:2825-2834.

32. Wang HC, Ma YB. Experimental models of traumatic axonal injury. J Clin Neurosci. 2010;17:157-162.

33. Morganti-Kossmann MC, Yan E, Bye N. Animal models of traumatic brain injury: is there an optimal model to reproduce human brain injury in the laboratory? Injury. 2010;41 Suppl 1:S10- S13.

34. Foda MA, Marmarou A. A new model of diffuse brain injury in rats. Part II: Morphological characterization. J Neurosurg. 1994;80:301-313.

35. Kelley BJ, Lifshitz J, Povlishock JT. Neuroinflammatory responses after experimental diffuse traumatic brain injury. J Neuropathol Exp Neurol. 2007;66:989-1001.

36. Oehmichen $M$, Theuerkauf I, Meissner C. Is traumatic axonal injury (AI) associated with an early microglial activation? Application of a double-labeling technique for simultaneous detection of microglia and AI. Acta Neuropathol. 1999;97:491-494.

37. Venkatesan C, Chrzaszcz M, Choi N, et al. Chronic upregulation of activated microglia immunoreactive for galectin-3/Mac-2 and nerve growth factor following diffuse axonal injury. J Neuroinflammation. 2010;7:32.

38. Yu I, Inaji M, Maeda J, et al. Glial cell-mediated deterioration and repair of the nervous system after traumatic brain injury in a rat model as assessed by positron emission tomography. J Neurotrauma. 2010;27:1463-1475.

39. Wilson $S$, Raghupathi $R$, Saatman KE, et al. Continued in situ DNA fragmentation of microglia/macrophages in white matter weeks and months after traumatic brain injury. J Neurotrauma. 2004;21:239-250.

40. Csuka E, Hans VH, Ammann E, et al. Cell activation and inflammatory response following traumatic axonal injury in the rat. Neuroreport. 2000;11:2587-2590.

41. Penkowa M, Giralt M, Lago N, et al. Astrocyte-targeted expression of IL-6 protects the CNS against a focal brain injury. Exp Neurol. 2003;181:130-148.

42. Fux M, van Rooijen N, Owens T. Macrophage-independent $\mathrm{T}$ cell infiltration to the site of injury-induced brain inflammation. J Neuroimmunol. 2008;203:64-72.

43. Scholz M, Cinatl J, Schadel-Hopfner M, et al. Neutrophils and the blood-brain barrier dysfunction after trauma. Med Res Rev. 2007;27:401-416.

44. Farias S, Frey LC, Murphy RC, et al. Injury-related production of cysteinyl leukotrienes contributes to brain damage following experimental traumatic brain injury. J Neurotrauma. 2009;26:1977-1986.

45. Bye N, Carron S, Han X, et al. Neurogenesis and glial proliferation are stimulated following diffuse traumatic brain injury in adult rats. J Neurosci Res. 2011;89:986-1000.

46. Hellewell SC, Yan EB, Agyapomaa DA, et al. Post-traumatic hypoxia exacerbates brain tissue damage: analysis of axonal injury and glial responses. J Neurotrauma. 2010;27:1997-2010.

47. Morganti-Kossmann MC, Rancan M, Stahel PF, et al. Inflammatory response in acute traumatic brain injury: a double-edged sword. Curr Opin Crit Care. 2002;8:101-105.

48. Shohami E, Novikov M, Bass R, et al. Closed head injury triggers early production of TNF alpha and IL-6 by brain tissue. J Cereb Blood Flow Metab. 1994;14:615-619.

49. Taupin V, Toulmond S, Serrano A, et al. Increase in IL-6, IL-1 and TNF levels in rat brain following traumatic lesion. Influence of pre- and post-traumatic treatment with Ro5 4864, a peripheral-type (p site) benzodiazepine ligand. J Neuroimmunol. 1993;42:177-185.

50. Kossmann T, Stahel PF, Lenzlinger PM, et al. Interleukin-8 released into the cerebrospinal fluid after brain injury is associated with blood-brain barrier dysfunction and nerve growth factor production. J Cereb Blood Flow Metab. 1997;17:280-289.

51. Balasingam $\mathrm{V}$, Tejada-Berges $\mathrm{T}$, Wright $\mathrm{E}$, et al. Reactive astrogliosis in the neonatal mouse brain and its modulation by cytokines. J Neurosci. 1994;14:846-856.

52. Holmin S, Schalling M, Hojeberg B, et al. Delayed cytokine expression in rat brain following experimental contusion. J Neurosurg. 1997;86:493-504.

53. Ciallella JR, Ikonomovic MD, Paljug WR, et al. Changes in expression of amyloid precursor protein and interleukin-1beta after experimental traumatic brain injury in rats. J Neurotrauma. 2002;19:1555-1567. 
54. Lu KT, Wang YW, Wo YY, et al. Extracellular signal-regulated kinase-mediated IL-1-induced cortical neuron damage during traumatic brain injury. Neurosci Lett. 2005;386:40-45.

55. Campbell SJ, Deacon RM, Jiang Y, et al. Overexpression of IL-1beta by adenoviral-mediated gene transfer in the rat brain causes a prolonged hepatic chemokine response, axonal injury and the suppression of spontaneous behaviour. Neurobiol Dis. 2007;27:151-163.

56. Hans VH, Kossmann T, Lenzlinger PM, et al. Experimental axonal injury triggers interleukin-6 mRNA, protein synthesis and release into cerebrospinal fluid. J Cereb Blood Flow Metab. 1999;19:184-194.

57. Rhodes JK, Andrews PJ, Holmes MC, et al. Expression of interleukin-6 messenger RNA in a rat model of diffuse axonal injury. Neurosci Lett. 2002;335:1-4.

58. Tilg H, Trehu E, Atkins MB, et al. Interleukin-6 (IL-6) as an anti-inflammatory cytokine: induction of circulating IL-1 receptor antagonist and soluble tumor necrosis factor receptor p55. Blood. 1994;83:113-118.

59. Scheller J, Chalaris A, Schmidt-Arras D, et al. The pro- and anti-inflammatory properties of the cytokine interleukin-6. Biochim Biophys Acta. 2011;1813:878-888.

60. Jawa RS, Anillo S, Huntoon K, et al. Interleukin-6 in surgery, trauma, and critical care part II: clinical implications. J Intensive Care Med. 2011;26:73-87.

61. Kita T, Tanaka T, Tanaka N, et al. The role of tumor necrosis factor-alpha in diffuse axonal injury following fluid-percussive brain injury in rats. Int J Legal Med 2000;113:221-228.

62. Khuman J, Meehan WP, 3rd, Zhu X, et al. Tumor necrosis factor alpha and Fas receptor contribute to cognitive deficits independent of cell death after concussive traumatic brain injury in mice. J Cereb Blood Flow Metab. 2011;31:778-789.

63. Yan EB, Hellewell SC, Bellander BM, et al. Post-traumatic hypoxia exacerbates neurological deficit, neuroinflammation and cerebral metabolism in rats with diffuse traumatic brain injury. J Neuroinflammation. 2011;8:147.

64. Hundsberger $\mathrm{H}$, Verin A, Wiesner $\mathrm{C}$, et al. TNF: a moonlighting protein at the interface between cancer and infection. Front Biosci. 2008;13:5374-5386.

65. Katschinski DM, Robins HI, Schad M, et al. Role of tumor necrosis factor alpha in hyperthermia-induced apoptosis of human leukemia cells. Cancer Res. 1999;59:3404-3410.

66. Akassoglou K, Bauer J, Kassiotis G, et al. Oligodendrocyte apoptosis and primary demyelination induced by local $\mathrm{TNF} / \mathrm{p} 55 \mathrm{TNF}$ receptor signaling in the central nervous system of transgenic mice: models for multiple sclerosis with primary oligodendrogliopathy. Am J Pathol. 1998;153:801-813

67. Ladiwala U, Lachance C, Simoneau SJ, et al. p75 neurotrophin receptor expression on adult human oligodendrocytes: signaling without cell death in response to NGF. J Neurosci. 1998;18:1297-1304.

68. Previtali SC, Archelos JJ, Hartung HP. Modulation of the expression of integrins on glial cells during experimental autoimmune encephalomyelitis. A central role for TNF-alpha. Am J Pathol. 1997;151:1425-1435.

69. Greenwood J, Etienne-Manneville S, Adamson P, et al. Lymphocyte migration into the central nervous system: implication of ICAM-1 signalling at the blood-brain barrier. Vascul Pharmacol. 2002;38:315-322.

70. Hausmann EH, Berman NE, Wang YY, et al. Selective chemokine mRNA expression following brain injury. Brain Res. 1998;788:49-59.

71. Rhodes JK, Sharkey J, Andrews PJ. The temporal expression, cellular localization, and inhibition of the chemokines MIP-2 and MCP-1 after traumatic brain injury in the rat. J Neurotrauma. 2009;26:507-525.

72. Rancan M, Otto VI, Hans VH, et al. Upregulation of ICAM-1 and MCP-1 but not of MIP-2 and sensorimotor deficit in response to traumatic axonal injury in rats. J Neurosci Res. 2001;63:438-446.

73. Schilling $M$, Strecker JK, Ringelstein EB, et al. The role of CC chemokine receptor 2 on microglia activation and blood-borne cell recruitment after transient focal cerebral ischemia in mice. Brain Res. 2009;1289:79-84.

74. Matzer SP, Zombou J, Sarau HM, et al. A synthetic, non-peptide CXCR2 antagonist blocks MIP-2-induced neutrophil migration in mice. Immunobiology. 2004;209:225-233.

75. Ueta M, Sotozono C, Yokoi N, et al. Prostaglandin E receptor subtype EP3 expression in human conjunctival epithelium and its changes in various ocular surface disorders. PLoS One. 2011;6:e25209.

76. Vane JR, Bakhle YS, Botting RM. Cyclooxygenases 1 and 2. Annu Rev Pharmacol Toxicol. 1998;38:97-120.

77. Brian JE, Jr., Moore SA, Faraci FM. Expression and vascular effects of cyclooxygenase-2 in brain. Stroke. 1998;29:2600-2606.
78. Tardieu D, Jaeg JP, Deloly A, et al. The COX-2 inhibitor nimesulide suppresses superoxide and 8-hydroxy-deoxyguanosine formation, and stimulates apoptosis in mucosa during early colonic inflammation in rats. Carcinogenesis. 2000;21:973-976.

79. Parsadaniantz SM, Lebeau A, Duval P, et al. Effects of the inhibition of cyclo-oxygenase 1 or 2 or 5-lipoxygenase on the activation of the hypothalamic-pituitary-adrenal axis induced by interleukin-1beta in the male Rat. J Neuroendocrinol. 2000;12:766-773.

80. Hickey RW, Adelson PD, Johnnides MJ, et al. Cyclooxygenase-2 activity following traumatic brain injury in the developing rat. Pediatr Res. 2007;62:271-276.

81. Kunz T, Marklund N, Hillered L, et al. Cyclooxygenase-2, prostaglandin synthases, and prostaglandin $\mathrm{H} 2$ metabolism in traumatic brain injury in the rat. J Neurotrauma. 2002;19:1051-1064.

82. Cernak I, O'Connor C, Vink R. Inhibition of cyclooxygenase 2 by nimesulide improves cognitive outcome more than motor outcome following diffuse traumatic brain injury in rats. Exp Brain Res. 2002;147:193-199.

83. Stahel PF, Morganti-Kossmann MC, Kossmann T. The role of the complement system in traumatic brain injury. Brain Res Brain Res Rev. 1998;27:243-256.

84. Stahel PF, Kossmann T, Morganti-Kossmann MC, et al. Experimental diffuse axonal injury induces enhanced neuronal C5a receptor mRNA expression in rats. Brain Res Mol Brain Res. 1997;50:205-212.

85. Trembovler V, Beit-Yannai E, Younis F, et al. Antioxidants attenuate acute toxicity of tumor necrosis factor-alpha induced by brain injury in rat. J Interferon Cytokine Res. 1999;19:791-795.

86. Yu JX, Bradt BM, Cooper NR. Constitutive expression of proinflammatory complement components by subsets of neurons in the central nervous system. J Neuroimmunol. 2002;123:91-101.

87. Risling M, Plantman S, Angeria M, et al. Mechanisms of blast induced brain injuries, experimental studies in rats. Neuroimage. 2011;54 Suppl 1:S89-S97.

88. Davidsson J AM, Risling M. Injury threshold for sagittal plane rotational induced diffuse axonal injuries. In: 2009 International ircobi conference on the biomechanics of injury (Schmitt, K. U., ed). YORK (UK): IRCOBI Conference. 2009;:43-56.

89. Sun X, Wang X, Chen T, et al. Myelin activates FAK/Akt/NF-kappaB pathways and provokes CR3-dependent inflammatory response in murine system. PLoS One. 2010;5:e9380.

90. Yang XF, Wang H, Wen L. From myelin debris to inflammatory responses: a vicious circle in diffuse axonal injury. Med Hypotheses. 2011;77:60-62.

91. Okonkwo DO, Melon DE, Pellicane AJ, et al. Dose-response of cyclosporin A in attenuating traumatic axonal injury in rat. Neuroreport. 2003;14:463-466.

92. Tamas A, Zsombok A, Farkas O, et al. Postinjury administration of pituitary adenylate cyclase activating polypeptide (PACAP) attenuates traumatically induced axonal injury in rats. J Neurotrauma. 2006;23:686-695.

93. Donkin JJ, Cernak I, Blumbergs PC, et al. A substance P antagonist reduces axonal injury and improves neurologic outcome when administered up to 12 hours after traumatic brain injury. J Neurotrauma. 2011;28:217-224.

94. Staal JA, Dickson TC, Chung RS, et al. Cyclosporin-A treatment attenuates delayed cytoskeletal alterations and secondary axotomy following mild axonal stretch injury. Dev Neurobiol. 2007;67:1831-1842.

95. Homsi S, Piaggio T, Croci N, et al. Blockade of acute microglial activation by minocycline promotes neuroprotection and reduces locomotor hyperactivity after closed head injury in mice: a twelve-week follow-up study. J Neurotrauma. 2010;27:911-921. 